\title{
Plant traits co-vary with altitude in grasslands and forests in the European Alps
}

\author{
Loïc Pellissier • Bertrand Fournier • \\ Antoine Guisan · Pascal Vittoz
}

Received: 8 January 2010/ Accepted: 21 May 2010/Published online: 12 June 2010

(C) Springer Science+Business Media B.V. 2010

\begin{abstract}
Biological traits that are advantageous under specific ecological conditions should be present in a large proportion of the species within an ecosystem, where those specific conditions prevail. As climatic conditions change, the frequency of certain traits in plant communities is expected to change with increasing altitude. We examined patterns of change for 13 traits in 120 exhaustive inventories of plants along five altitudinal transects $(520-3,100 \mathrm{~m}$ a.s.l.) in grasslands and in forests in western Switzerland. The traits selected for study represented the occupation of space, photosynthesis, reproduction and dispersal. For each plot, the mean trait values or the proportions of the trait states were weighted by species cover and examined in relation to the first axis of a PCA based on local climatic conditions. With
\end{abstract}

Electronic supplementary material The online version of this article (doi:10.1007/s11258-010-9794-x) contains supplementary material, which is available to authorized users.

L. Pellissier · A. Guisan · P. Vittoz ( $₫)$

Department of Ecology and Evolution, University

of Lausanne, Bâtiment Biophore, 1015 Lausanne,

Switzerland

e-mail: pascal.vittoz@unil.ch

B. Fournier

Laboratory of Soil Biology, University of Neuchâtel, 2009 Neuchâtel, Switzerland

P. Vittoz

Faculty of Geosciences and Environment, University of Lausanne, 1015 Lausanne, Switzerland increasing altitude in grasslands, we observed a decrease in anemophily and an increase in entomophily complemented by possible selfing; a decrease in diaspores with appendages adapted to ectozoochory, linked to a decrease in achenes and an increase in capsules. In lowlands, pollination and dispersal are ensured by wind and animals. However, with increasing altitude, insects are mostly responsible for pollination, and wind becomes the main natural dispersal vector. Some traits showed a particularly marked change in the alpine belt (e.g. the increase of capsules and the decrease of achenes), confirming that this belt concentrates particularly stressful conditions to plant growth and reproduction (e.g. cold, short growing season) that constrain plants to a limited number of strategies. One adaptation to this stress is to limit investment in dispersal by producing capsules with numerous, tiny seeds that have appendages limited to narrow wings. Forests displayed many of the trends observed in grasslands but with a reduced variability that is likely due to a shorter altitudinal gradient.

Keywords Alpine ecology - Biological traits . Environmental gradient - Plant functional type . Reproduction · Switzerland

\section{Introduction}

Climatic conditions are strong ecological drivers that sort plant species assemblages (e.g. Archibold 1995; 
Díaz et al. 1998; Illa et al. 2006; Cornwell and Ackerly 2009). In the European Alps, as altitude increases, the climate shifts toward more stressful conditions for plant growth: lower mean temperatures, higher precipitation, longer snow cover and, thus, a shorter growing season, lower atmospheric pressure and higher solar radiation that induces high temperatures at the ground level (Körner 2003, pp. 22-30, 36-37, 2007). As species distributions are limited by tolerance to environmental conditions, plant composition exhibits species turnover along altitudinal transects (e.g. Körner 2000; Theurillat et al. 2003).

Plants that share the same habitat often exhibit similar characteristics (i.e., morphology, reproduction, diaspore dispersal; see Weiher et al. 1999; Knevel et al. 2003), generally identified as biological traits. Indeed, the limited adaptive solutions to a given set of environmental conditions result in convergent evolution that decreases the amount of suitable traits. This phenomenon is sometimes compared to a "filter" that removes the species that lack the necessary biological traits (e.g. Weiher and Keddy 1995; Díaz et al. 1998; Cornwell and Ackerly 2009). Hence, advantageous traits in a given environment should be dominant, or at least used by a large proportion of the species (e.g. Weiher and Keddy 1995; Díaz et al. 1998; Pavon et al. 2000). In this respect, studies regarding variations in the frequency of biological traits along altitudinal gradients can provide invaluable information about the adaptive value of plant characteristics during climate change.

Variations in plant traits in relation to various ecological gradients are often the focus of studies. For example, Díaz et al. (1999) investigated the traits of shrubs on Mediterranean sand dunes that were related to water table height. In the Pyrenean range, Illa et al. (2006) studied the adaptation of plant communities by examining plant trait distribution across different landforms in the alpine belt. Although many studies have looked at changes across gradients, a literature review concluded that only a few have assessed the distribution of plant traits along an entire altitudinal gradient in temperate climates, and almost never at the community scale. Earlier articles are limited to single plant traits (e.g. Kühn et al. 2006; Zhu et al. 2009; Pellissier et al. 2010) or to various traits possessed by a single species (e.g. Metrosideros polymorpha, Geeske et al. 1994; Cordell et al. 1998; Fisher et al. 2007), or they are located in regions with climatic conditions incomparable to those of Central Europe (Díaz et al. 1998; Pavon et al. 2000). Altitudinal gradients in the Alps have generally been considered in terms of comparisons between the species collected at two sites (often lowland vs. alpine areas; e.g. Körner et al. 1989; Fabbro and Körner 2004; Pluess et al. 2005). Hence, studies generally lack observations at intermediate altitudes, making it impossible to assess whether adaptation is gradual or abrupt along the whole altitudinal gradient.

Alpine plants are recognised to be shorter, to have smaller leaves (Körner et al. 1989) with lower specific leaf area (SLA) than lowland plants (Körner 2003, p. 211). On the other hand, the drier conditions associated with warm lowlands favour sclerophyllous species (Barboni et al. 2004) with low SLA values (e.g. Cornwell et al. 2007; Mitchell et al. 2008). Plant size should therefore decrease with altitude, and they should display less scleromorphic leaves, but with unclear trend for SLA. Additionally, Bliss (1971) and Billings (1974) noted that vegetative reproduction was particularly frequent in alpine plants. Clonal growth complements or replaces sexual reproduction in the seasonally unsuitable climatic conditions of the alpine belt (Stöcklin 1999), whereas sexual reproduction contributes to population growth in more favourable years (Weppler et al. 2006). The importance of vegetative reproduction should increase with altitude in these conditions. It is often stated that pollinator activity decreases with increasing altitude (e.g. Arroyo et al. 1982), reducing the likelihood of entomophily. However, this statement is supported by few detailed studies (e.g. Bingham and Orthner 1998). Körner (2003, p. 264) concluded that insect pollinated species dominate in number in the alpine belt, but anemophily dominates in biomass due to the large area covered by Poaceae and Cyperaceae. Similarly, Kühn et al. (2006) observed an increasing proportion of insect pollinated species with altitude. Hence, entomophily should be proportionally more frequent at a higher altitude when speaking of species richness, but the trend becomes uncertain when each species is further weighted by its cover.

Baker (1972) and Moles et al. (2007), respectively, observed decreasing seed mass with increasing altitude and latitude. Similarly, Pakeman et al. (2008) showed that seed mass was negatively correlated with latitude and positively correlated with solar radiation; there were significant, negative correlations with 
temperature and degree-days only when seed mass was not weighted by abundance. Conversely, Landolt (1967) and Pluess et al. (2005) found that alpine species had heavier seeds than their close lowland relatives. The pattern of seed mass along the altitudinal gradient is thus unclear (Körner 2003, p. 270).

Wind has long been recognised as the dominant diaspore dispersal vector in alpine species (e.g. Vogler 1901; Müller-Schneider 1986; Willson et al. 1990). Tackenberg and Stöcklin (2008) showed that diaspores take advantage of the more frequent and strong vertical wind turbulence. However, wind is recognised as the dominant vector in grasslands in general, whereas zoochory (especially by birds and ants) is more common in forests (e.g. Willson et al. 1990; Ozinga et al. 2004).

Here, in order to have a better insight into plant trait distribution along full altitudinal gradients at the community level, we investigated the variations of 13 plant traits related to life form, leaf morphology and reproduction in 120 vegetation plots distributed along five wide elevation transects (520-3,100 m. a.s.l.) in Switzerland. Our aims were to clarify previously debated issues about traits distribution along altitudinal gradients (e.g. SLA, importance of entomophily in species cover, seed mass), and to confirm previously observed trends (e.g. decreasing scleromorphy, increasing vegetative reproduction with increasing altitude). Moreover, we aimed to compare the trends between grasslands and forests, and to study them continuously from lowlands to alpine summits in order to assess if changes are gradual or abrupt.

\section{Materials and methods}

Study area and sampling method

Five sites were selected in the Swiss mountains (Fig. 1) that represent a gradient from sub-oceanic (Jura Mountains and Outer Alps) to sub-continental climatic conditions (Inner Alps). At each site, a transect was established along the longest possible altitudinal gradient in well-drained grasslands and in forests (Table 1). Plots within the same transect had approximately the same slope and aspect and were separated from each other by an altitude of $100 \mathrm{~m}$. Altogether, 120 vegetation plots were inventoried (Table 1).

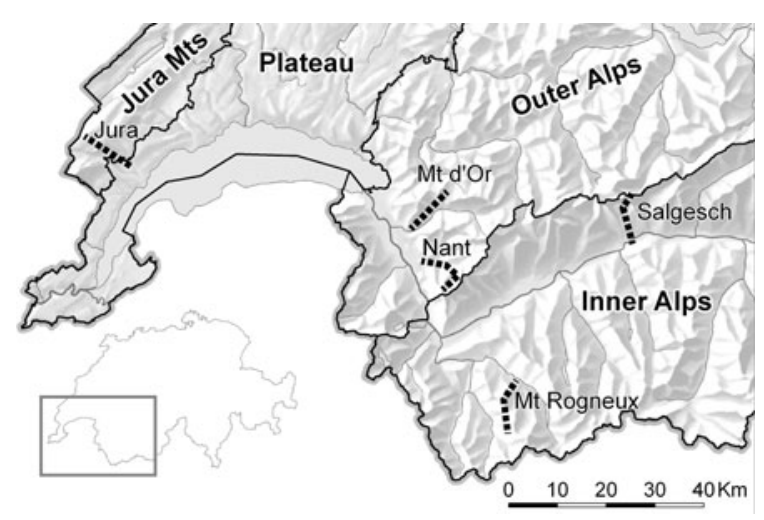

Fig. 1 Location of the five sites, each with two altitudinal transects in Switzerland (see Table 1 for plot distribution). Biogeographical regions are given in bold

Grasslands covered by dry sub-continental steppes were present in the lowlands (colline belt), while semi-dry central European meadows dominated the montane belt. Subalpine pastures with parts of heathlands were found around the treeline ecotone. Alpine grasslands were present in the alpine belt, and stable rock fields were found in the nival belt. The forests in the colline belt were dominated by Fagus sylvatica L. and Quercus petraea Liebl. in the Jura, Mt d'Or and Nant transects, whereas Quercus pubescens Willd. was the most common species in the Salgesch transect (Table 1). In the montane belt, Fagus sylvatica and Abies alba Mill. were the main components in the Jura and Mt d'Or transects; Picea abies (L.) H. Karst. in the Nant and Mt Rogneux transects; and Pinus sylvestris L. in the Salgesch transect. Picea abies dominated in all transects in the subalpine belt.

Exhaustive inventories were conducted on plots measuring $250 \mathrm{~m}^{2}$ in forests and $40 \mathrm{~m}^{2}$ in grasslands. Species cover was estimated visually into 10 classes following Vittoz and Guisan (2007): <0.1, 0.1-0.5, $0.5-1,1-3,3-5,5-15,15-25,25-50,50-75$ and $>75 \%$. Across all plots, 701 species were recorded.

Plant trait data

To address our aims, relevant plant life-history traits were selected and gathered from the literature. This approach was chosen because it would have been impossible to assess and measure all of the traits in the field given the considerable number of plots and species. Traits represented the following main plant 
Table 1 Location (biogeographical region), habitat type, number of plots, and altitude of the 10 transects in Switzerland

\begin{tabular}{|c|c|c|c|c|}
\hline Transect & Location & Habitat & Number of plots & Altitude [m a.s.1.] \\
\hline \multirow[t]{2}{*}{ Jura } & \multirow[t]{2}{*}{ Jura Mountains } & Forests & 10 & $540-1,450$ \\
\hline & & Grasslands & 6 & $1,040-1,540$ \\
\hline \multirow[t]{2}{*}{ Mt d'Or } & \multirow[t]{2}{*}{ Outer Alps } & Forests & 10 & $700-1,640$ \\
\hline & & Grasslands & 10 & $1,110-2,100$ \\
\hline \multirow[t]{2}{*}{ Nant } & \multirow[t]{2}{*}{ Outer Alps } & Forests & 12 & $520-1,640$ \\
\hline & & Grasslands & 10 & $1,240-2,640$ \\
\hline \multirow[t]{2}{*}{ Mt Rogneux } & \multirow[t]{2}{*}{ Inner Alps } & Forests & 9 & $1,190-1,990$ \\
\hline & & Grasslands & 13 & $2,100-3,043$ \\
\hline \multirow[t]{2}{*}{ Salgesch } & \multirow[t]{2}{*}{ Inner Alps } & Forests & 14 & $600-1,940$ \\
\hline & & Grasslands & 26 & $650-3,100$ \\
\hline
\end{tabular}

functions: occupation of the space (life form and height), photosynthesis (leaf persistence, form, anatomy and specific leaf area), reproduction (sexual vs. vegetative, pollen vector and fruit type) and dispersal (diaspore mass and length, presence of appendages and potential dispersal distance). For the analysis and coding of the diaspores, we considered the entire seed in most cases, including any appendages that promote dispersal. When the diaspore mass and length were not available, we used the seed characteristics as a substitute. Data were collected from different sources, including databases (Klotz et al. 2002; Flynn et al. 2006) and the literature (Müller-Schneider 1986; Lindacher et al. 1995; Stöcklin and Bäumler 1996; Cerabolini et al. 2003; Aeschimann et al. 2004; Austrheim et al. 2005; Pignatti 2005; Pluess et al. 2005; Römermann et al. 2005; Moles and Westoby 2006; Lindgren et al. 2007; Parolo and Rossi 2008; Vittoz et al. 2009). When possible, missing values were extrapolated from closely related species. Traits with many multiple states were simplified by grouping similar states together. The final traits and states that were analysed are listed in Table 2.

Analyses

Species present in fewer than three plots and with a cover that never exceeded 5\% were not retained for analysis. Trait values for such rare species are generally not available in databases, and because these species have low relative importance, this simplification is unlikely to affect the results. The number of species for which traits were investigated was therefore reduced to 475 . As we were interested in the influence of climate on plant communities, and particularly on the dominant traits, we weighted traits by cover in the analyses. The mean values of the respective cover classes used for the analyses were: $0.05,0.3,0.8,2,4,10,20,37.5,62.5$ and $82.5 \%$ (Vittoz and Guisan 2007). Since the same woody species can be present in the grass, shrub and tree layers in forests, only the cover in the highest stratum was retained. For each plot, the quantitative traits were averaged and weighted by plant cover, and the proportion of each trait state (also weighted by plant cover) was calculated for categorical traits.

Since climatic conditions can vary between transects within the same altitude, particularly if the Inner Alps are compared to the Jura Mountains, we applied a principal component analysis (PCA) to three environmental variables extracted from climatic maps (Zimmermann and Kienast 1999): degree-days above $3{ }^{\circ} \mathrm{C}$ (DDEG), moisture index (MIND, difference between precipitations and potential evapotranspiration in growing season) and solar radiation (SRAD, sum of potential direct and diffuse shortwave solar radiations in growing season). These environmental variables are recognised to be among the most important in explaining plant distribution in mountains and are commonly used in species distribution models because they are direct variables (Körner 2003; Guisan and Zimmermann 2000). For qualitative multiclass traits, we related the proportions (from 0 to 1 ) of the trait states to the first axis of the PCA using generalised linear mixed models (GLMM) in the lme4 package (Bates et al. 2007) of $R$ ( $R$ Development Core Team 2007) with a binomial distribution and a logistic link function. Similarly, for quantitative traits, we used linear mixed models (LMM) in the lme4 package. First, we computed 


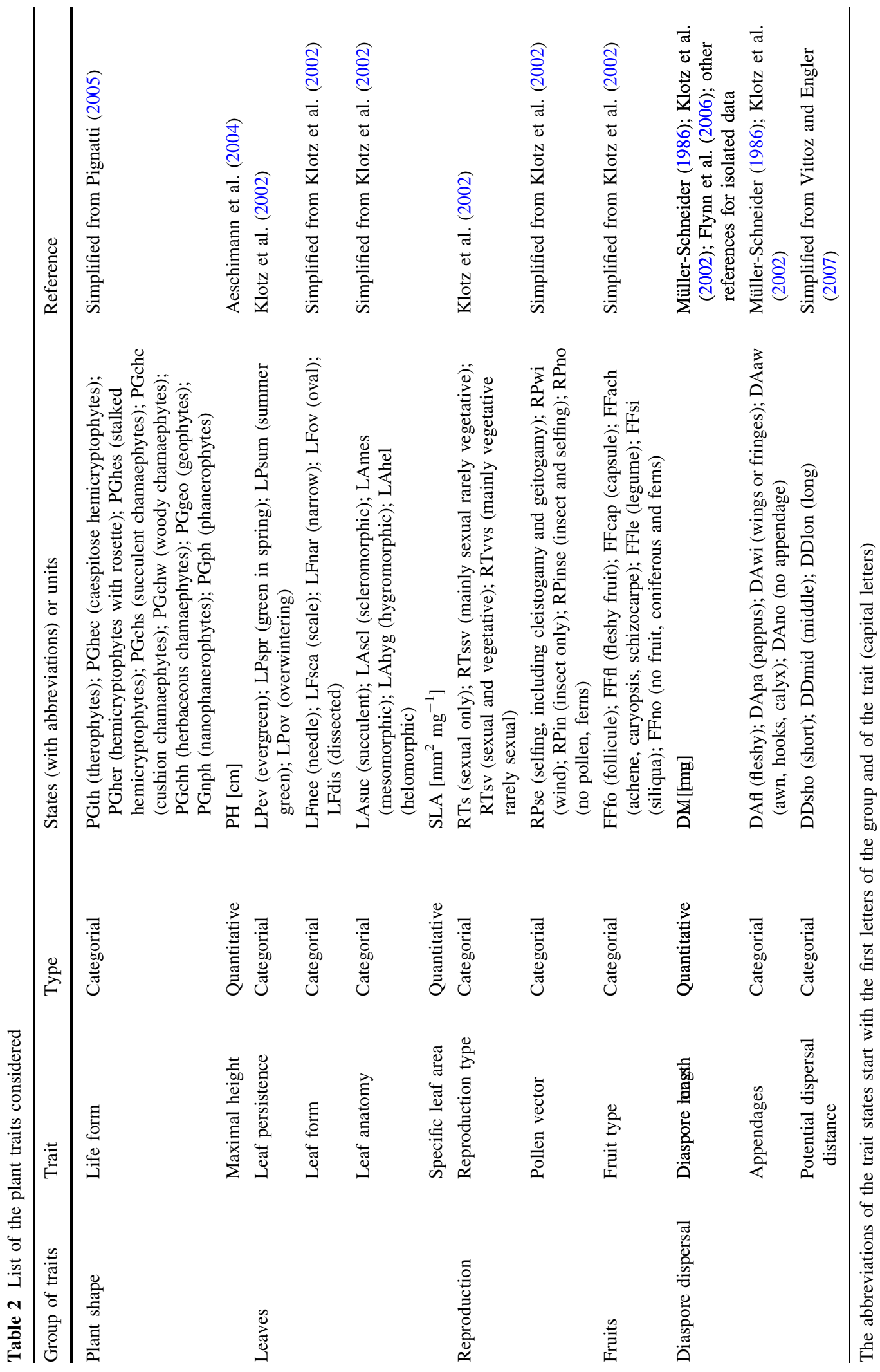


models with the first PCA axis and the habitat (grasslands or forests) as explanatory fixed factors and the transect in which the plots belong as the random factor. When the test indicated a significant difference between forests and grasslands for one of the trait states, we applied a model for this state independently to the forest and grassland plots but retained the random effect of the transects. The likelihoods of the models with binomial response variables were computed with the Laplace approximation as suggested by Bolker et al. (2009), while Monte-Carlo Chain simulation $(N=10,000)$ was used for models with Gaussian response variables using the pvals.fen function in the $\mathrm{R}$ package langageR.

As the analyses of the forest plots could be strongly influenced by the dominance of a few species in the tree layer, a second run was conducted using only the forest understory (herb and shrub layers). The results differed only for marginal points (see below) and were not retained in this article.

\section{Results}

The first axis of the PCA, which explained $64 \%$ of the variance, was mostly correlated to DDEG and MIND (See Supplementary Appendix 1). This axis corresponds to a gradient of altitude, with high DDEG and low MIND values corresponding to low altitude plots. Although we are aware that altitude is not a causal factor but rather translates factors, such as temperature and moisture, which are accounted for in the PCA, and others that are unaccounted for, like wind (Körner 2007), we will use altitude as a simplified reference to this gradient (See Supplementary Appen$\operatorname{dix} 2$ ).

\section{Life form}

The only significant trait along the first PCA axis (Table 3) was an increase in the proportion of cushion chamaephytes with altitude (Fig. 2a). This characteristic was particularly marked above $2,650 \mathrm{~m}$ a.s.l. Grasslands and forests behaved differently regarding hemicryptophytes (stalked and caespitose) and phanerophytes (Table 3). However, only caespitose hemicryptophytes showed a marginally significant decreasing trend with altitude in the individual models $(P=0.092$; see Supplementary Appendices 3 and 4 for the results of the individual models). This change was linked to a decrease in the maximum size of the plants at higher altitudes, which was also only significant in grasslands $(P=0.011$; Supplementary Appendix 4).

\section{Leaves}

The models showed that mesomorphic and scale leaves increased in proportion with altitude. The change in scale leaves was abrupt above $2,750 \mathrm{~m}$. Conversely, leaves were less frequently scleromorphic along the same gradient (Table 3; Fig. 2b). Needles, narrow leaves and the specific leaf area (SLA) behaved differently in grasslands and in forests. Narrow leaves decreased significantly with altitude in grasslands $(P=0.043)$, while no trend was shown for needles and SLA in either grasslands or forests (See Supplementary Appendices 3 and 4).

\section{Reproduction type}

Regarding the general trends, we found an increasing proportion of plants with mainly vegetative reproduction and of species pollinated by insects with possible selfing toward higher altitudes (Fig. 2c). The proportion of plants with sexual only, mainly sexual, sexual or vegetative reproduction and those pollinated by wind or by insects had a different comportment in grasslands and forests (Table 3). However, only wind pollination showed a trend in the individual models. The proportion of anemophilous species decreased marginally but significantly with altitude in grasslands $(P=0.073$; Fig. $2 \mathrm{~d})$.

\section{Fruits}

The proportion of plants producing capsules increased toward higher altitudes (Table 3). The proportion of plants bearing achenes (including caryopsis and schizocarpes) decreased significantly in grasslands $(P=0.022)$ and forests $(P=0.023$; Fig. 2e), while the proportion of plants without fruits increased marginally but significantly with altitude in forests $(P=0.075)$. The proportion of plants with capsules showed a particularly strong increase above 2,300 m (Fig. 2f). 
Table 3 Results of the GLMM of the trait states present in the plots with the first axis of the environmental PCA for grasslands and forests analysed simultaneously

\begin{tabular}{|c|c|c|c|c|c|c|}
\hline \multirow[t]{2}{*}{ Group of traits } & \multirow[t]{2}{*}{ Trait } & \multirow[t]{2}{*}{ Trait states } & \multicolumn{2}{|c|}{ PCA axis 1} & \multicolumn{2}{|c|}{ Forests/grasslands } \\
\hline & & & $Z$ & $P$ value & $Z$ & $P$ value \\
\hline \multirow[t]{11}{*}{ Plant shape } & \multirow[t]{11}{*}{ Growth form } & PGth (therophytes) & 0.17 & 0.864 & 0.36 & 0.718 \\
\hline & & PGhec (caespitose hemicryptophytes) & 1.87 & 0.061 & 3.41 & $<0.001$ \\
\hline & & PGher (hemicryptophytes with rosette) & -1.22 & 0.221 & 1.10 & 0.270 \\
\hline & & PGhes (stalked hemicryptophytes) & 0.36 & 0.716 & 2.33 & $\mathbf{0 . 0 2 0}$ \\
\hline & & PGchs (succulent chamaephytes) & 0.89 & 0.375 & 0.00 & 0.999 \\
\hline & & PGchc (cushion chamaephytes) & -2.07 & 0.038 & 0.00 & 0.998 \\
\hline & & PGchw (woody chamaephytes) & -0.20 & 0.839 & 1.88 & 0.060 \\
\hline & & PGchh (herbaceous chamaephytes) & -1.23 & 0.219 & 0.53 & 0.594 \\
\hline & & PGgeo (geophytes) & -0.05 & 0.958 & -0.98 & 0.328 \\
\hline & & PGnph (nanophanerophytes) & 0.03 & 0.974 & -0.35 & 0.725 \\
\hline & & PGph (phanerophytes) & 1.01 & 0.313 & -2.89 & 0.004 \\
\hline \multirow[t]{14}{*}{ Leaves } & \multirow[t]{4}{*}{ Leaf persistence } & LPev (evergreen) & -1.54 & 0.125 & 0.16 & 0.875 \\
\hline & & LPspr (green in spring) & 0.18 & 0.859 & 0.18 & 0.859 \\
\hline & & LPsum (summer green) & 1.56 & 0.119 & -0.20 & 0.845 \\
\hline & & LPov (overwintering) & -0.35 & 0.725 & 0.15 & 0.877 \\
\hline & \multirow[t]{5}{*}{ Leaf form } & LFnee (needle) & -1.28 & 0.200 & -4.02 & $<0.001$ \\
\hline & & LFsca (scale) & -2.11 & 0.035 & 0.37 & 0.711 \\
\hline & & LFnar (narrow) & 2.12 & 0.034 & 4.07 & $<0.001$ \\
\hline & & LFov (ovale) & 0.43 & 0.668 & -1.28 & 0.202 \\
\hline & & LFdis (dissected) & -0.33 & 0.743 & 1.45 & 0.148 \\
\hline & \multirow[t]{5}{*}{ Leaf anatomy } & LAsuc (succulent) & 0.89 & 0.375 & 0.00 & 0.999 \\
\hline & & LAscl (scleromorphic) & 2.02 & 0.043 & -0.21 & 0.837 \\
\hline & & LAmes (mesomorphic) & -1.97 & 0.049 & 0.50 & 0.618 \\
\hline & & LAhyg (hygromorphic) & -0.98 & 0.329 & -1.46 & 0.144 \\
\hline & & LAhel (helomorphic) & -0.04 & 0.972 & 0.07 & 0.947 \\
\hline \multirow[t]{9}{*}{ Reproduction } & \multirow[t]{4}{*}{ Reproduction type } & RTs (sexual only) & 0.55 & 0.586 & -4.92 & $<0.001$ \\
\hline & & RTssv (mainly sexual rarely vegetative) & 1.03 & 0.304 & 2.59 & 0.010 \\
\hline & & RTsv (sexual and vegetative) & -0.34 & 0.732 & 2.99 & 0.003 \\
\hline & & RTvvs (mainly vegetative rarey sexual) & -2.08 & $\mathbf{0 . 0 3 7}$ & -0.16 & 0.873 \\
\hline & \multirow[t]{5}{*}{ Pollen vector } & RPse (selfing) & 0.17 & 0.866 & 0.85 & 0.395 \\
\hline & & RPwi (wind) & 2.24 & 0.025 & -2.80 & 0.005 \\
\hline & & RPin (insect only) & -0.41 & 0.679 & 2.20 & 0.028 \\
\hline & & RPinse (insect and selfing) & -1.87 & 0.050 & 1.01 & 0.315 \\
\hline & & RPno (no pollen, ferns) & -0.95 & 0.343 & -1.04 & 0.297 \\
\hline \multirow[t]{7}{*}{ Fruits } & \multirow[t]{7}{*}{ Fruit type } & FFfo (follicule) & 0.63 & 0.529 & 0.98 & 0.325 \\
\hline & & FFfl (fleshy fruit) & -0.95 & 0.342 & -1.29 & 0.199 \\
\hline & & FFcap (capsule) & -2.31 & 0.021 & 1.66 & 0.096 \\
\hline & & FFach (achene, caryopsis, schizocarpe) & 3.03 & 0.002 & 3.18 & 0.001 \\
\hline & & FFle (legume) & 0.04 & 0.971 & 1.00 & 0.319 \\
\hline & & FFsi (siliqua) & -0.38 & 0.706 & -0.14 & 0.891 \\
\hline & & FFno (no fruit, coniferous and ferns) & -1.70 & 0.089 & -3.63 & $<0.001$ \\
\hline
\end{tabular}


Table 3 continued

\begin{tabular}{|c|c|c|c|c|c|c|}
\hline \multirow[t]{2}{*}{ Group of traits } & \multirow[t]{2}{*}{ Trait } & \multirow[t]{2}{*}{ Trait states } & \multicolumn{2}{|c|}{ PCA axis 1} & \multicolumn{2}{|c|}{ Forests/grasslands } \\
\hline & & & $Z$ & $P$ value & $Z$ & $P$ value \\
\hline \multirow[t]{8}{*}{ Diaspore dispersal } & \multirow[t]{5}{*}{ Appendages } & DAfl (fleshy) & -0.93 & 0.355 & -1.17 & 0.241 \\
\hline & & DApa (pappus) & -2.28 & 0.023 & 0.46 & 0.648 \\
\hline & & DAwi (wings or fringes) & -2.82 & 0.005 & -4.69 & $<0.001$ \\
\hline & & DAaw (awn, hooks, calyx) & 2.28 & 0.023 & 4.11 & $<0.001$ \\
\hline & & DAno (no appendage) & 1.90 & 0.058 & 0.75 & 0.451 \\
\hline & \multirow[t]{3}{*}{ Dispersal distance } & DDsho (short) & 0.05 & 0.964 & 3.18 & 0.002 \\
\hline & & DDmid (middle) & -0.98 & 0.325 & -0.65 & 0.514 \\
\hline & & DDlon (long) & 0.68 & 0.495 & -2.58 & 0.010 \\
\hline
\end{tabular}

Bold values indicate $P<0.05$, italic values indicate $P<0.1$

Diaspore dispersal

We observed decreasing diaspore length with increasing altitude (Table 4). The proportion of plants whose seeds have a pappus increased with altitude (Fig. $2 \mathrm{~g}$; Table 3), while plants with no appendages increased marginally but significantly along the same gradient. The proportion of plants with wings, awns, long and short dispersal distances, and diaspore mass was different in grasslands and forests. In grasslands, diaspores with wings were more frequent at higher altitudes $(P=0.035$; Fig. $2 \mathrm{~h})$, particularly above 2,650 $\mathrm{m}$, while diaspores with an awn were found more frequently at lower altitudes $(P=0.036)$. In forests, diaspore mass was found to decrease with altitude $(P=0.001$; Fig. $2 \mathrm{i})$.

\section{Discussion}

Plants are not distributed randomly in the environment. Rather, their distribution is related to functional adaptations developed to ecological conditions. The ability of a plant to adapt to ecological conditions can be related to morphological or physiological properties displayed by its organs (Halloy and Mark 1996). Therefore, by studying the frequency of the life history traits in several environments, one can assess if a trait reflects an adaptation to environmental pressures. In this context, we investigated several plant traits indicative of ecological properties (i.e., occupation of space, photosynthesis, reproduction and dispersal) and related them to the altitude gradient.
Plant shape

Short size and prostrate stature are certainly the most prominent characteristics of alpine plants (Billings 1974; Körner et al. 1989), and our analyses showed a decreasing trend of plant size with increasing altitude in grasslands. This trait was related to a decreasing proportion of caespitose hemicryptophytes toward higher altitudes. In lowlands and intermediate altitudes, this form is efficient at occupying space with lateral growth (phalanx strategy, Herben et al. 1993). With a decreasing length in the growing season, especially in the upper alpine belt, plants have limited time to grow and complete their life cycle. The cushion chamaephyte life form seems to be a good answer to this constraint in the upper alpine belt. These plants can survive above ground because of the probably lower winter wildlife grazing than in lowlands (covered by snow and thus protected from the larger herbivores), and this position provides them with quicker growth in the spring. Because of their short stature, these plants benefit from the heat that accumulates in the soil, and their compact form is good for heat storage (Körner 2003, pp. 39-40), provides protection against wind and allows efficient recycling of nutrients and water storage in rocky conditions (Körner 2003, p. 146).

Therophytes are generally considered to be less frequent in the alpine belt than in the lowlands (Körner 2003, p. 19), but this was not observed with our data. In fact, such a trend was graphically visible in grasslands (result not shown), but with a high variability between plots and a proportion of 

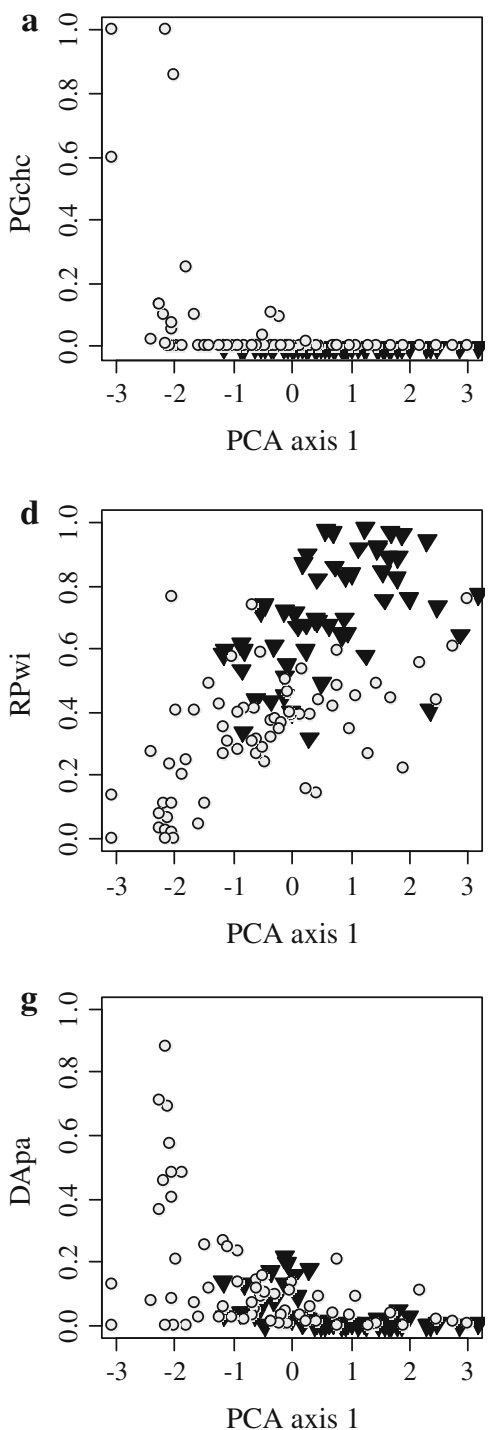
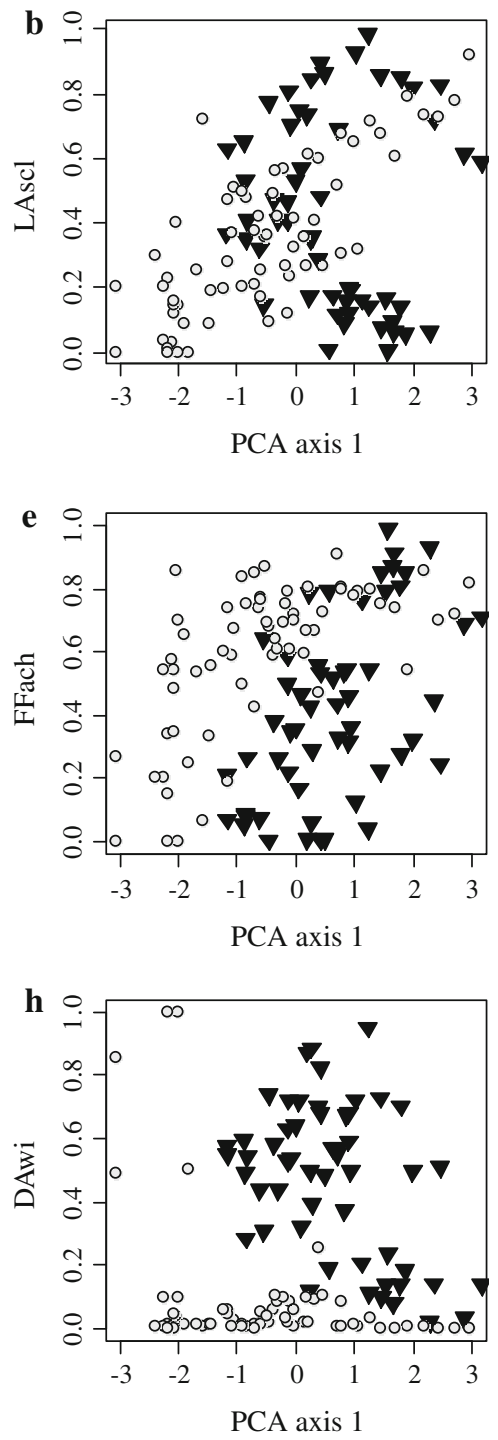
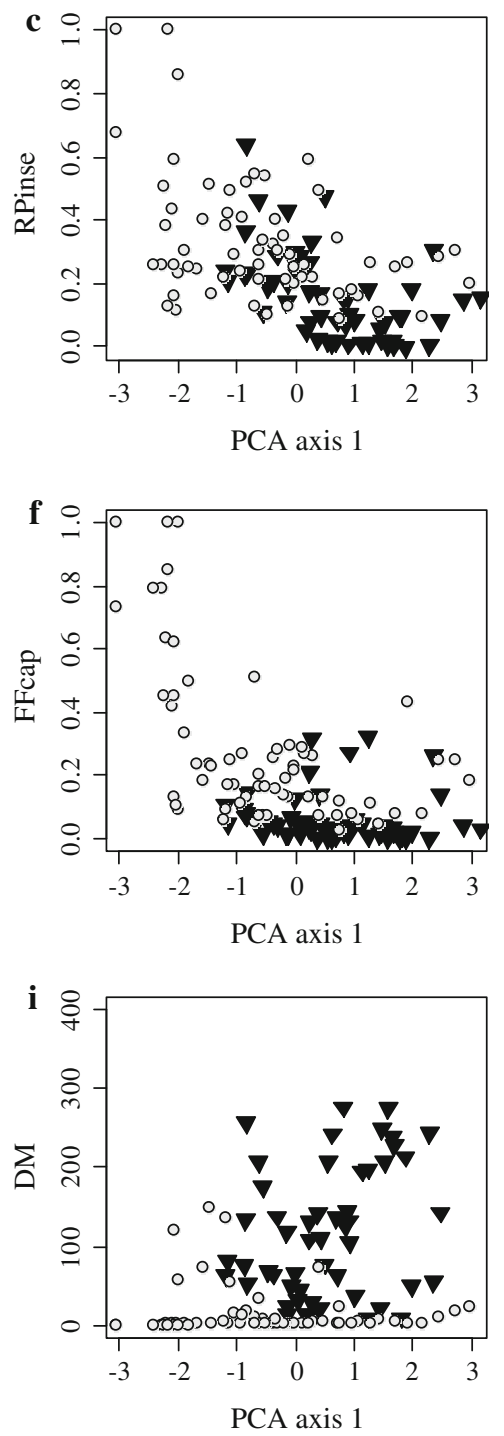

Fig. 2 Relationship between the first axis of the environmental PCA and the proportion of trait dominance. Life forms: a cushion chamaephytes (PGchc). Leaf anatomy: b scleromorphic. Pollen vectors: $\mathbf{c}$ insects with possible selfing (RPinse); d wind (RPwi). Fruit types: e achenes including caryopsis

therophytes that only rarely exceeded 5\%, which probably explains the absence of significant trend in analyses.

\section{Leaves}

Both environments had a higher proportion of scleromorphic leaves in lowlands, complemented in grasslands by narrow leaves. These traits represent an adaptation to summer drought associated with and schizocarpes (FFach); f capsules (FFcap). Appendages: g pappus (DApa); $\mathbf{h}$ wings or fringes (DAwi); $\mathbf{i}$ diaspore mass (DM). Gray circles indicate grasslands and black triangles forests

elevated temperatures (Burghardt and Riederer 2003), especially in the sub-continental climate of the Inner Alps where the warmest plots were found. Narrow leaves have a surface area large enough for photosynthesis in sunny conditions, and the scleromorphy protects against excessive evapotranspiration (e.g. de Bie et al. 1998). In forests, the trend of scleromorphy was accentuated by the high cover of Pinus sylvestris in the sub-continental region. Such morphology is even more frequently found in the 
Table 4 Results of the LMM of the trait mean values in the plots with the first axis of the environmental PCA for grasslands and forests analysed simultaneously

\begin{tabular}{|c|c|c|c|c|c|c|c|c|c|}
\hline \multirow[t]{2}{*}{ Group of traits } & \multirow[t]{2}{*}{ Trait } & \multicolumn{4}{|c|}{ PCA axis 1} & \multicolumn{4}{|c|}{ Forests/grasslands } \\
\hline & & Estimate & HPD95lower & HPD95upper & $P$ value & Estimate & HPD95lower & HPD95upper & $P$ value \\
\hline Plant shape & Maximal height & 7.0 & -93.7 & 109.0 & 0.900 & -2772.7 & -3044.2 & -2513.4 & $<0.001$ \\
\hline Leaves & $\begin{array}{l}\text { Specific leaf area } \\
\text { (SLA) }\end{array}$ & -0.3 & -0.8 & 0.3 & 0.300 & 2.4 & 1.1 & 3.7 & $<0.001$ \\
\hline \multirow{2}{*}{$\begin{array}{l}\text { Diaspore } \\
\text { dispersal }\end{array}$} & Diaspore mass & 29.4 & 7.0 & 54.6 & $<0.001$ & -117.2 & -178.4 & -48.4 & $<0.001$ \\
\hline & Diaspore length & 5.3 & 3.6 & 7.2 & $<0.001$ & 1.8 & -2.6 & 6.9 & 0.389 \\
\hline
\end{tabular}

Bold values indicate $P<0.05$

summer-dry, Mediterranean region $(\sim 300 \mathrm{~km}$ further south than the study area) with Quercus ilex L. or Q. suber L. forests (Archibold 1995; Díaz et al. 1999).

In the upper alpine and nival belts, scale leaves became common but were present in a limited number of species (mainly Saxifraga bryoides L., S. oppositifolia L. and Androsace alpina (L.) Lam.). These very small leaves contribute to the small, prostrate shape of alpine plants and are mainly found in cushion plants (Körner et al. 1989).

We did not observe any significant trend for SLA along our transects. This could be explained by the opposition of two previously observed tendencies for SLA: lower SLA values in dry sites (i.e. lowlands in Inner Alps) than in humid environments (e.g. Cornwell et al. 2007; Mitchell et al. 2008) and lower SLA values at high altitude than in lowlands (Körner 2003, pp. 211-213). Moreover, these studies showed strong intraspecific variations of SLA, with an important phenotypic component. SLA values measured directly at the sites would be necessary to address more precisely this question.

With broadleaved forests in the lowlands and conifer forests in the subalpine belt, we expected a decrease in oval leaves and an increase of needles with altitude. However, these characteristics were only present in the tree layer but not in the understory, and analyses did not show any significant trend.

Reproduction type and pollen vector

Vegetative reproduction was more frequent at higher altitudes. In subalpine forests, it was mainly due to two dominant species of the understory (Vaccinium myrtillus L. and V. vitis-idaea L.), which are frequent around treeline in Switzerland. Similarly, in alpine grasslands, the trend was strongly influenced by a limiting number of species: the dwarf Salix herbacea L., the tussock Carex curvula All. and the viviparous Polygonum viviparum L. This strategy might provide a successful way to reproduce during unfavourable years in mountain climatic conditions (Weppler et al. 2006).

Regarding pollen vectors, forests and grasslands showed the same trend with altitude of increasing entomophily and possible selfing; grasslands showed a decreasing cover of species using anemophily. These results suggest that if insects effectively tend to be less frequent and less active in the alpine belt (e.g. Arroyo et al. 1982; Berry and Calvo 1989), they still prove to be a more efficient pollen vector than wind (in grasslands, entomophily with selfing is proportionally more important than wind pollination above $\sim 2,000 \mathrm{~m}$ ). It has been proposed that wind pollination evolved in response to pollinator limitations of insect pollinated species (Cox and Grubb 1991; Goodwillie 1999). This method has the advantages of requiring simpler structures (no big, scented and showy flowers) and the independence from insects for pollination. Moreover, anemophily would be advantageous in alpine grasslands because of the open structure of grasslands (Culley et al. 2002). However, wind pollination needs a relatively dry environment for longer pollen viability because pollen is eliminated by precipitation (Whitehead, 1969). Tormo Molina et al. (2001) showed that Plantago pollen dispersal was negatively affected by air humidity and moisture. With an increasing precipitation gradient with altitude (Sevruk 1997), it is possible that wind pollination loses efficiency in alpine environment and 
is then replaced by insects. However, because of the uncertain climatic conditions, insect pollinated species tolerate selfing as an alternative to insects when weather conditions are unfavourable.

\section{Diaspore mass}

Previous studies of seed mass along altitudinal gradients showed contrasting results (see synthesis in Körner 2003, pp. 269-270). Baker (1972) and Moles et al. (2007) observed decreasing seed mass with decreasing temperature, but Landolt (1967) and Pluess et al. (2005) found that alpine species had heavier seeds as compared to closely related species in the lowlands. However, comparisons are difficult because there are large differences between taxonomic groups (e.g. legumes have much heavier seeds than other forbs; Baker 1972), and in most studies, only the seeds were used, whereas the complete diaspores (including awns, wings or flesh) were considered in our work. We found a significant decrease with increasing altitude in the diaspore mass in forests but not in grasslands. In grasslands, diaspores had a constant mass below 2,000 m, a maximum around 2,200 $\mathrm{m}$ (around the treeline) and mainly low masses above 2,500 m (See Supplementary Appendix 5). The maximum value in the middle of a long gradient can explain the lack of a significant trend in the linear model. However, the decrease in the alpine belt is clear. Decreasing diaspore mass is probably linked to the highly significant decrease in diaspore length.

Diaspore mass has to be considered in relation to fruit type, which influences the number, size and type of diaspores. In forests, the trend was influenced by the tree layer with large achenes (Fagus-beechnuts and Quercus-acorns) in lowlands and the absence of real fruits (cones of Abies, Picea and Larix) with light seeds found in the mountain conifer forests. The shift of diaspore types and the decreasing diaspore mass were no more significant in forests when only the understory was considered (results not shown). At the treeline, the maximum mass values that were observed in grasslands, which corresponded to a few particularly high values in the highest forests as well (Fig. 2i), were due to the high cover of some species with fleshy diaspores (Juniperus communis subsp. alpina (Suter) Celak., Vaccinium spp., Empetrum nigrum subsp. hermaphroditum (Hagerup)
Böcher). In the alpine belt, the trend of lighter diaspores was consistent with more capsules and less achenes (including caryopses and schizocarpes) at higher altitudes. Capsules generally contain numerous small seeds, dispersed mainly by wind, while achenes are larger and often dispersed with appendages (see below; Müller-Schneider 1986).

Dispersal vector

Multiple dispersal vectors are common in plants (e.g. Müller-Schneider 1986; Willson et al. 1990; Vittoz and Engler 2007), with different vectors sometimes retained for a single species. Given this trend, we chose to investigate the potential dispersal vector indirectly with the diaspore morphology (appendages; Willson et al. 1990). We observed a decrease in diaspores with awns (including hooks and calyces) or nude diaspores and an increase for those with pappus or wings that correlated with increasing altitude. Hence, two opposite strategies for dispersal can be recognised along the altitudinal gradient. Diaspores with appendages (awn, hook or calyx) are efficiently dispersed by ectozoochory (e.g. Fischer et al. 1996; Römermann et al. 2005) but potentially by anemochory as well (Tackenberg 2001). The nude diaspores in the lowland are probably dispersed by dyszoochory when they are large and selected by animals (Müller-Schneider 1986) or by endozoochory when they are small and eaten with grass (Janzen 1984). Some nude diaspores use wind when capsules are shaken (boleochory; Müller-Schneider 1986). In both cases, anemochory is probably more frequent but less efficient for dispersing over long distances (Tackenberg 2001; Vittoz and Engler 2007) than zoochory. In the lower alpine belt, efficient wind conditions for anemochory (Tackenberg and Stöcklin 2008) and perhaps lower mammal density seem to favour diaspores with pappus. The latter are more efficient in wind than awns (Vogler 1901; Tackenberg 2001) and stick to animal fur as well (Römermann et al. 2005). Growing seasons become shorter with increasing altitude and plants become smaller. As seen above, diaspore mass diminishes (See Supplementary Appendix 5) and capsules become more frequent (Fig. 2f) in the alpine belt. Simultaneously, the proportion of pappus seems to decrease abruptly above 2,650 m (Fig. 2g). Capsules may represent an efficient dispersal system because of the 
large number of small and light seeds they contain. Very light seeds $(<0.05 \mathrm{mg})$ are as efficient as seeds with pappus for dispersal (Bonn and Poschlod 1998), and the strong winds with upward turbulences in mountains are efficient dispersal vectors (Tackenberg and Stöcklin 2008). Moreover, these small seeds offer the economy of energetically costly appendages (awn, hooks or pappus), or the appendage is limited to very narrow wings at the highest altitudes (Vogler 1901; Fig. 2h), which improves dispersal efficiency as shown in the alpine summit colonisation study by Vittoz et al. (2009).

Gradual or abrupt changes along the gradient?

We observed a gradual change with increasing altitude for most of the plant traits. However, within the grasslands, some of the traits showed a pattern of drastic change beyond a threshold, after a long interval with limited variation. These thresholds were always observed in the alpine belt: an increase in the capsule and a decrease in the achene proportion above 2,300 $\mathrm{m}$ a.s.l., a decrease in diaspore mass above $2,500 \mathrm{~m}$, an increase in cushion chamaephytes and diaspores with narrow wings or fringes above $2,650 \mathrm{~m}$ and an increase in scale leaves above 2,750 $\mathrm{m}$. These sudden changes demonstrate a transition to more stressful conditions that are close to the physiological limits for growth, which constrain plants to a limited number of possibilities (Körner 2003). Low stature plants, such as cushions, dominate. The small size and short vegetation period probably constrain reproduction toward small diaspores without appendages, to reduce the energy necessary for reproduction. Similar transects in other regions and experiments implying physiological measurements would allow us to assess if such thresholds are a constant in the alpine belt and to improve our understanding of the phenomenon.

Forests and grasslands: differences and similarities

Most of the observed trends were common to grasslands and forests, suggesting that these two vegetation types have globally similar adaptations to common ecological constrains. Forests, however, exhibited a lower variability along the altitudinal gradient than grasslands. Only two trends were specific to forests, the increasing absence of fruits and the decreasing diaspore mass toward higher altitudes, but both were strongly linked to the tree layer (no more significant when only the understory was considered), while seven trends were specific to grasslands: increasing cushion chamaephytes and diaspores with wings; decreasing plant height, caespitose hemicryptophytes, narrow leaves, anemophily and diaspores with awns, hooks or calyx toward higher altitudes. The reduced variability of plant traits can be explained by the shorter altitudinal gradient in forests $(540-1,990 \mathrm{~m})$ compared to grasslands (650$3,100 \mathrm{~m}$ ) and by the buffered conditions of the forest understory (e.g. Otto 1998; Kromer et al. 2007). Plants need less adaptation in these more homogeneous climatic conditions.

\section{Conclusions}

Eleven of the 13 functional traits in plants that were considered showed a trend in their mean value (quantitative traits), or at least one of their states (qualitative multiclass traits), along the altitudinal gradient. Some of the observed changes are quite trivial and have been previously observed (e.g. decreasing plant size), but others had never been assessed before on such a long altitudinal gradient in two different vegetation structures at the community scale.

Altogether, our results showed that plants tend to use opposite vectors for pollination and diaspore dispersal along the altitudinal gradient. In lowlands, wind and animals contribute to pollination and dispersal. With increasing altitude, insects become more important for pollination when wind dominates dispersal. At the highest altitudes (upper alpine to nival belts), plants strongly reduce their investment in dispersal by producing capsules with numerous, tiny seeds, with possible appendages limited to narrow wings.

The data presented here are representative of five transects in a limited area, and some of the observed trends may be specific to the regional flora. These observed trends may not be directly applicable to other regions with different floras. Similar observations in other ranges would be very useful to have a more global understanding of the plant adaptations (in terms of trait variation) along altitudinal gradients. 
The study of the relationship between the environment and plant traits might bring a better understanding of the assemblage and composition of plant communities.

Acknowledgements This research was supported by the Federal Office for the Environment FOEN (Switzerland), Centre de conservation de la faune et de la nature (Canton de Vaud), Fondation Audemars Piguet, the European Commission (ECO CHANGE and MACIS FP6-projects) and NSF grant Nr. 31003A125145 (BIOASSEMBLE project). We are grateful to S. Jutzeler, S. Maire and F. Dessimoz for assistance with field work, to J. Goudet and J. Dwyer for their advice in statistical analysis and to G. Besnard and two anonymous reviewers for their useful comments on earlier versions of the manuscript.

\section{References}

Aeschimann D, Lauber K, Moser DM, Theurillat J-P (2004) Flora Alpina. Belin, Paris

Archibold OW (1995) Ecology of world vegetation. Chapman \& Hall, London

Arroyo MTK, Primack R, Armesto J (1982) Community studies in pollination ecology in the high temperate Andes of Central Chile. I. Pollination mechanisms and altitudinal variation. Am J Bot 69:82-97

Austrheim G, Evju M, Mysterud A (2005) Herb abundance and life-history traits in two contrasting alpine habitats in southern Norway. Plant Ecol 179:217-229

Baker HG (1972) Seed weight in relation to environmental conditions in California. Ecology 53:997-1010

Barboni D, Harrison SP, Bartlein PJ, Jalut G, New M, Prentice IC, Sanchez-Goni MF, Spessa A, Davis B, Stevenson AC (2004) Relationships between plant traits and climate in the Mediterranean region: a pollen data analysis. J Veg Sci 15:635-646

Bates D, Maechler M, Dai B (2007) lme4: linear mixed-effects models using S4 classes. Version 0.999375-28. http://cran. r-project.org

Berry PE, Calvo RN (1989) Wind pollination, self-incompatibility, and altitudinal shifts in pollination systems in the High Andean genus Espeletia Asteraceae. Am J Bot 76: 1602-1614

Billings WD (1974) Adaptations and origins of alpine plants. Arct Alp Res 6:129-142

Bingham RA, Orthner AR (1998) Efficient pollination of alpine plants. Nature 391:238-239

Bliss LC (1971) Arctic and alpine plant life cycles. Annu Rev Ecol Syst 2:405-438

Bolker BM, Brooks ME, Clark CJ, Geange SW, Poulsen JR, Stevens MH, White JS (2009) Generalized linear mixed models: a practical guide for ecology and evolution. Trends Ecol Evol 24:127-135

Bonn S, Poschlod P (1998) Ausbreitungsbiologie der Pflanzen Mitteleuropas. Quelle and Meyer UTB, Wiesbaden

Burghardt M, Riederer M (2003) Ecophysiological relevance of cuticular transpiration of deciduous and evergreen plants in relation to stomatal closure and leaf water potential. J Exp Bot 54:1941-1949

Cerabolini B, Ceriani RM, Caccianiga M, Andreis RD, Raimondi B (2003) Seed size, shape and persistence in soil: a test on Italian flora from Alps to Mediterranean coasts. Seed Sci Res 13:75-85

Cordell S, Goldstein G, Mueller-Dombois D, Webb D, Vitousek PM (1998) Physiological and morphological variation in Metrosideros polymorpha, a dominant Hawaiian tree species, along an altitudinal gradient: the role of phenotypic plasticity. Oecologia 113:188-196

Cornwell WK, Ackerly DD (2009) Community assembly and shifts in plant trait distributions across an environmental gradient in coastal California. Ecol Monogr 79:109-126

Cornwell WK, Bhaskar R, Sack L, Cordell S, Lunch CK (2007) Adjustment of structure and function of Hawaiian Metrosideros polymorpha at high vs. low precipitation. Funct Ecol 21:1063-1071

Cox PA, Grubb PJ (1991) Abiotic pollination: an evolutionary escape for animal-pollinated angiosperms. Philos Trans R Soc Lond B Biol Sci 333:217-224

Culley TM, Weller SG, Sakai AK (2002) The evolution of wind pollination in angiosperms. Trends Ecol Evol 17:361-369

de Bie S, Ketner P, Paasse M, Geerling C (1998) Woody plant phenology in the West Africa savanna. J Biogeogr 25: 883-900

Díaz S, Cabido M, Casanoves F (1998) Plant functional traits and environmental filters at a regional scale. J Veg Sci 9:113-122

Díaz BMC, Zunzunegui M, Tirado R, Ain-Lhout F, Novo FG (1999) Plant functional types and ecosystem function in Mediterranean shrubland. J Veg Sci 10:709-716

Fabbro T, Körner C (2004) Altitudinal differences in flower traits and reproductive allocation. Flora 199:70-81

Fischer SF, Poschlod P, Beinlich B (1996) Experimental studies on the dispersal of plants and animals on sheep in calcareous grasslands. J Appl Ecol 33:1206-1222

Fisher JB, Goldstein G, Jones TJ, Cordell S (2007) Wood vessel diameter is related to elevation and genotype in the Hawaiian tree Metrosideros polymorpha Myrtaceae. Am J Bot 94:709-715

Flynn S, Turner RM, Stuppy WH (2006) Seed information database release 7.0, October 2006. http://www.kew.org/ data/sid

Geeske J, Aplet G, Vitousek PM (1994) Leaf morphology along environmental gradients in Hawaiian Metrosideros polymorpha. Biotropica 26:17-22

Goodwillie C (1999) Wind pollination and reproductive assurance in Linanthus parviflorus Polemoniaceae, a selfincompatible annual. Am J Bot 86:948-954

Guisan A, Zimmermann N (2000) Predictive habitat distribution model in ecology. Ecol Mod 135:147-186

Halloy SRP, Mark AF (1996) Comparative leaf morphology spectra of plant communities in New Zealand, the Andes and the European Alps. J R Soc New Zeal 26:41-78

Herben T, Krahulec F, Hadincova V, Kovarova M (1993) Small-scale spatial dynamics of plant-species in a grassland community over 6 years. J Veg Sci 4:171-178

Illa E, Carrillo E, Ninot JM (2006) Patterns of plant traits in Pyrenean alpine vegetation. Flora 201:528-546 
Janzen DH (1984) Dispersal of small seeds by big herbivores: foliage is the fruit. Am Nat 123:338-353

Klotz S, Ingolf K, Durka W (2002) BIOLFOR-Eine Datenbank mit biologisch-ökologishen Merkmalen zur Flora von Deutschland. Schriftenreihe für Vegetationskunde 38, Bundesamt für Naturschutz, Bonn

Knevel IC, Bekker RM, Bakker JP, Klyer M (2003) Life-history traits of the Northwest European flora: the LEDA database. J Veg Sci 14:611-614

Körner C (2000) Why are there global gradients in species richness? Mountains might hold the answer. Trends Ecol Evol 15:513-514

Körner C (2003) Alpine plant life, 2nd edn. Springer, Berlin

Körner C (2007) The use of 'altitude' in ecological research. Trends Ecol Evol 22:569-574

Körner C, Neumayer M, Menendez-Riedl SP, Smeets-Scheel A (1989) Functional morphology of mountain plants. Flora 182:353-383

Kromer T, Kessler M, Gradstein SR (2007) Vertical stratification of vascular epiphytes in submontane and montane forest of the Bolivian Andes: the importance of the understory. Plant Ecol 189:261-278

Kühn I, Bierman SM, Durka W, Klotz S (2006) Relating geographical variation in pollination types to environmental and spatial factors using novel statistical methods. New Phytol 172:127-139

Landolt E (1967) Gebirgs- und Tieflandsippen von Blütenpflanzen im Bereich der Schweizer Alpen. Bot Jahrb 86: 463-480

Lindacher R, Böcker R, Bemmerlein-Lux FA, Kleemann A, Haas S, Sukopp H (1995) PHANART. Datenbank des Gefässpflanzen Mitteleuropas. Erklärung der Kennzahlen, Aufbau und Inhalt. Veröff Geobot Inst ETH Stiftung Rübel Zürich 125:1-436

Lindgren A, Eriksson O, Moen J (2007) The impact of disturbance and seed availability on germination of alpine vegetation in the Scandinavian Mountains. Arct Alp Res 39:449-454

Mitchell P, Veneklaas E, Lambers H, Burgess S (2008) Using multiple trait associations to define hydraulic functional types in plant communities of south-western Australia. Oecologia 158:385-397

Moles AT, Westoby M (2006) Seed size and plant strategy across the whole life cycle. Oikos 113:91-105

Moles AT, Ackerly DD, Tweddle JC, Dickie JB, Smith R, Leishman MR, Mayfield MM, Pitman A, Wood JT, Westoby M (2007) Global patterns in seed size. Global Ecol Biogeogr 16:109-116

Müller-Schneider P (1986) Verbreitungsbiologie der Blütenpflanzen Graubündens. Veröff Geobot Inst ETH Stiftung Rübel Zürich 85:1-263

Otto H-J (1998) Ecologie forestière. Institut pour le développement forestier, Paris

Ozinga WA, Bekker RM, Schaminée JHJ, van Groenendael JM (2004) Dispersal potential in plant communities depends on environmental conditions. J Ecol 92:767-777

Pakeman RJ, Garnier E, Lavorel S, Ansquer P, Castro H, Cruz P, Doležal J, Eriksson O, Freitas H, Golodets C, Kigel J, Kleyer M, Lepš J, Meier T, Papadimitriou M, Papanastasis VP, Quested H, Quétier F, Rusch G, Sternberg M, Theau JP, Thébault A, Vile D (2008) Impact of abundance weighting on the response of seed traits to climate and land use. J Ecol 96:355-366

Parolo G, Rossi G (2008) Upward migration of vascular plants following a climate warming trend in the Alps. Basic Appl Ecol 9:100-107

Pavon NP, Hernandez-Trejo H, Rico-Gray V (2000) Distribution of plant life forms along an altitudinal gradient in the semiarid valley of Zapotitlan, Mexico. J Veg Sci 11:39-42

Pellissier L, Pottier J, Vittoz P, Dubuis A, Guisan A (2010). Spatial pattern of floral morphology: an insight into the effects of pollinators on plant distributions? Oikos. doi: 10.1111/j.1600-0706.2010.18560.x

Pignatti S (2005) Valory di bioindicazione delle piante vascolari della flora d'Italia. Braun-Blanquetia 39:1-97

Pluess AR, Schütz W, Stöcklin J (2005) Seed weight increases with altitude in the Swiss Alps between related species but not among populations of individual species. Oecologia 144:55-61

R Development Core Team (2007) R: a language and environment for statistical computing. R Foundation for Statistical Computing, Vienna, Austria. http://www.R-project.org

Römermann C, Tackenberg O, Poschlod P (2005) How to predict attachment potential of seeds to sheep and cattle coat from simple morphological seed traits. Oikos 110: 219-230

Sevruk B (1997) Regional dependency of precipitation-altitude relationship in the Swiss Alps. Clim Chang 36:355-369

Stöcklin J (1999) Differences in life history traits of related Epilobium species: clonality, seed size and seed number. Folia Geobot 34:7-18

Stöcklin J, Bäumler E (1996) Seed rain, seedling establishment and clonal growth strategies on a glacier foreland. J Veg Sci 7:45-56

Tackenberg O (2001) Methoden zur Bewertung gradueller Unterschiede des Ausbreitungspotentials von Pflanzenarten. PhD Thesis, Philipps-Universität Marburg, Marburg/Lahn

Tackenberg O, Stöcklin J (2008) Wind dispersal of alpine plant species: a comparison with lowland species. J Veg Sci 19:109-118

Theurillat J-P, Schlüssel A, Geissler P, Guisan A, Velluti C, Wiget L (2003) Vascular plant and bryophyte diversity along elevation gradients in the Alps. In: Nagy L, Grabherr G, Körner C, Thompson DBA (eds) Alpine biodiversity in Europe. Ecological studies 167. Springer Verlag, Heidelberg, pp 185-193

Tormo Molina R, Silva Palacios I, Munoz Rodriguez AF, Tavira Munoz J, Moreno Corchero A (2001) Environmental factors affecting airborne pollen concentration in anemophilous species of Plantago. Ann Bot 87:1-8

Vittoz P, Engler R (2007) Seed dispersal distances: a typology based on dispersal modes and plant traits. Bot Helv 117:109-124

Vittoz P, Guisan A (2007) How reliable is the monitoring of permanent vegetation plots? A test with multiple observers. J Veg Sci 18:413-422

Vittoz P, Dussex N, Wassef J, Guisan A (2009) Plant traits discriminate good from weak colonisers on high elevation summits. Basic Appl Ecol 10:508-515

Vogler P (1901) Über die Verbreitungsmittel der schweizerischen Alpenpflanzen. Flora oder Allgem Bot Zeit 89: 1-137 
Weiher E, Keddy P (1995) Assembly rules, null models, and trait dispersion: new questions from old patterns. Oikos 74:159-164

Weiher E, van der Werf A, Thompson K, Roderick M, Garnier E, Eriksson O (1999) Challenging Theophrastus: a common core list of plant traits for functional ecology. J Veg Sci 10:609-620

Weppler T, Stoll P, Stöcklin J (2006) The relative importance of sexual and clonal reproduction for population growth in the long-lived alpine plant Geum reptans. J Ecol 94:869-879

Whitehead DR (1969) Wind pollination in the angiosperms: evolutionary and environmental considerations. Evolution 23:28-35
Willson MF, Rice BL, Westoby M (1990) Seed dispersal spectra: a comparison of temperate plant communities. J Veg Sci 1:547-562

Zhu Y, Jiang Y, Liu Q, Kang M, Spehn EM, Körner Ch (2009) Elevational trends of biodiversity and plant traits do not converge - a test in the Helan Range, NW China. Plant Ecol 205:273-283

Zimmermann NE, Kienast F (1999) Predictive mapping of alpine grasslands in Switzerland: species versus community approach. J Veg Sci 10:469-482 